\title{
Mortality associated with delay in operation after hip fracture: observational study
}

Alex Bottle, Paul Aylin

\begin{abstract}
Objective To estimate the number of deaths and readmissions associated with delay in operation after femoral fracture.

Design Analysis of inpatient hospital episode statistics.

Setting NHS hospital trusts in England with at least 100 admissions for fractured neck of femur during the study period. Patients People aged $\geq 65$ admitted from home with fractured neck of femur and discharged between April 2001 and March 2004.
\end{abstract}

Main outcome measures In hospital mortality and emergency readmission within 28 days.

Results There were 129522 admissions for fractured neck of femur in 151 trusts with 18508 deaths in hospital (14.3\%). Delay in operation was associated with an increased risk of death in hospital, which was reduced but persisted after adjustment for comorbidity. For all deaths in hospital, the odds ratio for more than one day's delay relative to one day or less was 1.27 (95\% confidence interval 1.23 to 1.32$)$ after adjustment for comorbidity. The proportion with more than two days' delay ranged from $1.1 \%$ to $62.4 \%$ between trusts. If death rates in patients with at most one day's delay had been repeated throughout all 151 trusts in this study, there would have been an average of 581 (478 to 683 ) fewer total deaths per year $(9.4 \%$ of the total). There was little evidence of an association between delay and emergency readmission.

Conclusions Delay in operation is associated with an increased risk of death but not readmission after a fractured neck of femur, even with adjustment for comorbidity, and there is wide variation between trusts.

\section{Introduction}

Each year, about 60000 hip fractures occur in the United Kingdom, principally in elderly women, with mortality $10-20 \%$ above that expected on the basis of age and sex. ${ }^{1}$ The importance of delay in operation (the time between admission to hospital and corrective operation) is "inconclusive." In older patients, a valid reason for delay is the need to stabilise concurrent medical conditions. A Swedish study found that a delay of up to a week did not result in more complications. ${ }^{3}$ In contrast, two studies found that delay increased the risk of death and morbidity even in physiologically stable patients. ${ }^{45}$ The Royal College of Physicians' guidelines recommend that patients should be operated on within 24 hours of admission. ${ }^{6}$ In practice, this may be hard to achieve.

We estimated the association between operative delay in patients admitted from home with a fractured hip and death in hospital and emergency readmission rates within 28 days of discharge using routine hospital data.

\section{Methods}

We examined data from the hospital episode statistics for the period April 2001 to March 2004 for all NHS hospitals in England and extracted records of patients aged $\geq 65$ with a primary diagnosis of fractured hip (ICD-10 (international classification of disease, 10th revision) codes S720-S722) admitted from their home. We excluded those admitted from nursing and residential homes (using the source of admission field) to ensure a more homogeneous premorbid health status. ${ }^{3}$ Only a patient's first admission for hip fracture was included. Patients were allocated to one of four treatment categories according to the first orthopaedic procedure (with an OPCS4 (operative procedure classification system code) beginning with $\mathrm{W}$, if any) identified from an inspection of each procedure field in each episode in turn of the admission: fixation (W19, W20, W24, W25 covering primary open or closed reduction and internal or external fixation), prosthetic replacement of head of femur (W46-W48), any other procedure (including non-orthopaedic ones if no fixation or replacement procedure was recorded anywhere in the admission), and no procedure recorded ("medical management"). Records with an unknown or invalid date of procedure were excluded. We included all hospital trusts with $>100$ admissions for fractured hip over three years.

We used two definitions of delay: more than one day (if the date of the operation was two or more days later than the admission date) and more than two days (if the gap was three or more days). For each patient, we use three outcome measures: any death in hospital during the initial admission for the fracture, death in hospital within 30 days of the initial admission, and emergency readmission within 28 days of discharge at the end of the initial admission.

Logistic regression models were fitted for each outcome with these covariates: age group (five year bands up to 90-94, then $\geq 95$ ), sex, treatment category, and fifth of ward level socioeconomic deprivation with the 2004 index of multiple deprivation. ${ }^{7}$ The secondary diagnosis fields were used to derive several binary comorbidity variables: dementia or Alzheimer's (ICD-10 codes F00-F03, G30), diabetes (E10-E14), chronic ischaemic heart disease (I20, I23-I25), chronic lower respiratory disease (J40-J47), heart failure (I50), hypertensive disease (I10-I15), renal failure (N17-N19), and malignancy (any C code). As the goal was confounder control, all covariates were retained in the models. Random effects models with PROC NLMIXED in $\mathrm{SAS}^{8}$ were then fitted with delay as the outcome (for patients 
Table 1 Basic figures (for all three years combined) for 2001-2 to 2003-4 for all NHS hospitals in England

\begin{tabular}{|c|c|c|c|c|}
\hline Measure & $\begin{array}{c}\text { No } \\
\text { procedure }\end{array}$ & Fixation & Replacement & $\begin{array}{c}\text { Other } \\
\text { procedure }\end{array}$ \\
\hline Admissions & 9206 & 62177 & 52765 & 5374 \\
\hline $\begin{array}{l}\text { Deaths in hospital (within } 30 \text { days } \\
\text { of admission) }\end{array}$ & $\begin{array}{l}3195 \\
(2779)\end{array}$ & 7681 (4895) & 6548 (4096) & $1084(827)$ \\
\hline $\begin{array}{l}\text { Death rate (within } 30 \text { days of } \\
\text { admission) }\end{array}$ & $\begin{array}{l}34.7 \\
(30.2)\end{array}$ & $12.4(7.9)$ & $12.4(7.8)$ & $20.2(15.4)$ \\
\hline Median age & 84 & 83 & 83 & 81 \\
\hline $\begin{array}{l}\text { Emergency readmission rate within } \\
28 \text { days (min-max) }\end{array}$ & $\begin{array}{c}12.2 \\
(0-40.9)\end{array}$ & $9.1(0-19.0)$ & $\begin{array}{c}9.2 \\
(2.4-17.1)\end{array}$ & $9.1(0-50.0)$ \\
\hline $\begin{array}{l}\% \text { with } \leq 1 \text { day delay (median, } \\
\text { min-max) }\end{array}$ & - & $\begin{array}{l}60.7(63.1 \\
15.9-99.3)\end{array}$ & $\begin{array}{l}59.4(61.7 \\
18.9-98.4)\end{array}$ & $\begin{array}{c}52.2(51.5, \\
5.9-89.2)\end{array}$ \\
\hline $\begin{array}{l}\% \text { with } \leq 2 \text { day delay (median, } \\
\text { min-max) }\end{array}$ & - & $\begin{array}{l}79.2(82.5 \\
34.9-99.3)\end{array}$ & $\begin{array}{l}78.1(80.6 \\
40.8-98.4)\end{array}$ & $\begin{array}{c}67.0(67.7, \\
11.8-100)\end{array}$ \\
\hline $\begin{array}{l}\text { Median length of stay initial acute } \\
\text { hospital (IQR) for survivors only }\end{array}$ & $\begin{array}{c}12 \\
(5-27)\end{array}$ & $18(11-32)$ & $18(11-30)$ & $18(11-33)$ \\
\hline $\begin{array}{l}\text { Median total length of stay } \\
\text { including post-transfer hospital } \\
\text { spells (IQR) for survivors only }\end{array}$ & $\begin{array}{c}14 \\
(6-33)\end{array}$ & $21(12-40)$ & $20(13-37)$ & $20(12-39)$ \\
\hline $\begin{array}{l}\text { \% survivors transferred to another } \\
\text { NHS hospital }\end{array}$ & 18.6 & 19.4 & 18.9 & 16.9 \\
\hline $\begin{array}{l}\text { \% survivors transferred to other } \\
\text { intermediate care }{ }^{*}\end{array}$ & 14.9 & 15.2 & 14.3 & 13.6 \\
\hline
\end{tabular}

$\mathrm{IQR}=$ interquartile range

*Nursing home, local authority care home, hospice, or non-NHS institution.

having fixation or replacement procedures only) to take account of the "clustering" of patients within trusts.

We estimated the number of outcome events associated with delay for patients having fixation or replacement operations only. Using regression, we derived the predicted probability of death for patients in each stratum from those with at most one day's delay. These probabilities were then multiplied by the number of patients in each stratum at each trust and summed by trust to obtain the total number of expected events (deaths or deaths at 30 days) for the trust. We calculated the difference between the actual (observed) number of events and the expected number for each trust, with $95 \%$ confidence intervals for the difference derived by assuming that the observed events followed an overdispersed Poisson distribution.

\section{Results}

\section{Numbers of admissions and procedures}

There were 151 trusts with at least 100 admissions for hip fracture, yielding 129522 admissions in patients aged $\geq 65$ during the three years. A total of 18508 died in hospital (14.3\%), of whom 2068 (11.2\%) died in another NHS hospital after transfer. Another 7428 admissions were excluded because of invalid data (mainly duplicate records and invalid dates of admission or discharge).

Overall, only $9206(7.1 \%)$ had no procedure recorded (table 1), ranging from $0.8 \%$ to $23.2 \%$ between trusts. The mean number of fixation and replacement procedures was 761 per trust (range 80-1854). The proportion waiting more than one day or more than two days varied more than twofold between trusts.

Comorbidity was more common in surgical patients with delay compared with those with at most one day's delay and those managed medically (table 2). The differences in proportions across the delay groups in table 2 were highly significant for each variable $(\mathrm{P}<0.001$, except $\mathrm{P}=0.081$ for hypertension, Cochran-Armitage tests for trend).
Table 2 Frequency of comorbidity variables with respect to presence and timing of surgery. Figures are numbers (percentages) of patients

\begin{tabular}{lccccc} 
Comorbidity & $\mathbf{1}$ day delay* & 2 day delay & >2 day delay* & No procedure \\
\hline Heart failure & $2705(3.9)$ & $974(4.6)$ & $1979(8.1)$ & $960(10.4)$ \\
\hline Chronic IHD & $5949(8.7)$ & $2091(9.8)$ & $2962(12.1)$ & $1299(14.1)$ \\
\hline Renal failure & $1105(1.6)$ & $441(2.1)$ & $743(3.1)$ & $441(4.8)$ \\
\hline Dementia & $8169(11.9)$ & $2773(13.0)$ & $3142(12.9)$ & $1201(13.1)$ \\
\hline Diabetes & $4675(6.8)$ & $1591(7.5)$ & $1910(7.8)$ & $692(7.5)$ \\
\hline Lower RTI & $4719(6.9)$ & $1652(7.8)$ & $2358(9.7)$ & $1006(10.9)$ \\
\hline Malignancy & $1524(2.2)$ & $551(2.6)$ & $751(3.1)$ & $379(4.1)$ \\
\hline Hypertension & $11923(17.3)$ & $3928(18.5)$ & $4599(18.9)$ & $1322(14.4)$ \\
\hline Other comorbidity & $19156(27.9)$ & $6009(28.2)$ & $7105(29.1)$ & $2602(28.3)$ \\
\hline$\geq 3$ comorbidities & $1863(2.7)$ & $700(3.9)$ & $1161(4.8)$ & $522(5.7)$ \\
\hline $\begin{array}{l}\text { No comorbidity } \\
\text { recorded }\end{array}$ & $20104(29.2)$ & $5245(24.7)$ & $4793(19.7)$ & $1839(20.0)$ \\
\hline All patients $\dagger$ & 68771 & 21275 & 24389 & 9206
\end{tabular}

RTI=respiratory tract infection; IHD=ischaemic heart disease.

${ }^{\star}$ For those with replacement or fixation procedures and valid dates of operation only. †Sum to more than total because patients can have more than one comorbidity.

\section{Factors associated with mortality and emergency} readmission

Table 3 gives odds ratios for mortality in hospital and emergency readmission for each factor considered. Age, sex, and fifth of deprivation were highly significant $(\mathrm{P}<0.001$, Wald tests) for all outcomes, and comorbidity factors were usually significant.

The most common single cause (primary diagnosis) of emergency readmission within 28 days was hip fracture $(11.9 \%$ for all patients and $10.2 \%$ for those having either a fixation or replacement), followed by "complications of internal prosthetic devices, implants and grafts" (ICD-10 T84, 7.2\%) and unspecified pneumonia $(J 18,5.5 \%)$. The data do not allow us to distinguish between new and existing fractures.

\section{Effect of type of surgery and operative delay}

Fixation and replacement procedures had similar mortality and readmission rates; patients with some other operation had almost twice the death rate and those with no operation had the highest rate of all. For patients having either a fixation or replacement, $11.0 \%$ of readmissions were for "complications of surgical and medical care not elsewhere classified" (codes T80-T88). These were more common after a replacement $(14.5 \%$ $v 8.1 \%, \mathrm{P}<0.001, \chi^{2}$ test).

Overall, $39.9 \%$ of procedures were performed more than one day after admission (range between trusts 1.1\%-82.7\%) and $21.3 \%$ were delayed more than two days (1.1\%-62.4\%). Delay rates were similar for the two main procedure types but slightly more common in the oldest patients $(35.9 \%$ in the $65-69$ age range had more than one day's delay compared with $40.3 \%$ in those aged $\geq 95$ ).

Variables associated with higher rates of delay were older age, female, the four most deprived fifths, replacement procedure, and each comorbidity variable (table 3 ). For patients having only either a fixation or a replacement procedure and death or 30 day death as the outcome, age, sex, and fifth of deprivation were again highly significant, as was operative delay (both categories) and the comorbidity variables $(\mathrm{P}<0.001$, Wald tests). For readmissions, there was little evidence of an effect of delay (odds ratio $1.04, \mathrm{P}=0.13$, for more than one day's delay and 1.04 , $\mathrm{P}=0.15$, for more than two days' delay) (table 4).

Adjustment for comorbidity reduced the estimated effect of delay. For all deaths in hospital, the odds ratio for more than one day's delay fell from 1.39 (95\% confidence interval 1.34 to 1.44$)$ to 1.27 (1.23 to 1.32) and that for more than two days' delay fell from 1.60 (1.54 to 1.67 ) to 1.43 (1.37 to 1.49 ) after adjustment for 
Research

Table 3 Odds ratios (95\% confidence intervals) for death and readmission for age, sex, deprivation fifth, and comorbidity

\begin{tabular}{|c|c|c|c|c|}
\hline \multirow[b]{2}{*}{ Factor and category } & \multirow[b]{2}{*}{ No $(\%)$} & \multicolumn{3}{|c|}{ Outcome } \\
\hline & & Death in hospital & $\begin{array}{c}\text { Death in hospital within } 30 \text { days of } \\
\text { admission }\end{array}$ & Emergency readmission within 28 days \\
\hline \multicolumn{5}{|l|}{ Sex: } \\
\hline Male & $26430(20.6)$ & 1.89 (1.82 to 1.97$)$ & 1.85 (1.78 to 1.92$)$ & 1.33 (1.26 to 1.39 ) \\
\hline Female & $101860(79.4)$ & 1 & 1 & 1 \\
\hline \multicolumn{5}{|l|}{ Age: } \\
\hline$\geq 95$ & $6008(4.7)$ & 9.52 (8.33 to 10.9$)$ & 8.49 (7.27 to 9.91$)$ & 1.63 (1.42 to 1.87$)$ \\
\hline $90-94$ & $19319(15.1)$ & 6.44 (5.69 to 7.30$)$ & 5.36 (4.63 to 6.20$)$ & 1.56 (1.40 to 1.75$)$ \\
\hline $85-89$ & $30612(23.9)$ & 4.26 (3.77 to 4.82$)$ & 3.61 (3.13 to 4.17$)$ & 1.47 (1.32 to 1.63$)$ \\
\hline $80-84$ & $31810(24.8)$ & 3.00 (2.65 to 3.39$)$ & 2.62 (2.27 to 3.03 ) & 1.32 (1.19 to 1.47$)$ \\
\hline $75-79$ & $22120(17.2)$ & 2.10 (1.84 to 2.38$)$ & 1.88 (1.62 to 2.19$)$ & 1.27 (1.14 to 1.42 ) \\
\hline $70-74$ & $12107(9.4)$ & 1.50 (1.30 to 1.72) & 1.38 (1.18 to 1.63 ) & 1.12 (1.00 to 1.26$)$ \\
\hline $65-69$ & $6314(4.9)$ & 1 & 1 & 1 \\
\hline \multicolumn{5}{|l|}{ Fifth of deprivation*: } \\
\hline 1 (most deprived) & $24716(19.3)$ & 1.19 (1.12 to 1.25$)$ & 1.18 (1.11 to 1.25 ) & 1.32 (1.23 to 1.41$)$ \\
\hline 2 & $25718(20.1)$ & 1.10 (1.04 to 1.16$)$ & 1.10 (1.03 to 1.17$)$ & 1.20 (1.13 to 1.29$)$ \\
\hline 3 & $26723(20.8)$ & $1.00(0.95$ to 1.06$)$ & 1.03 (0.96 to 1.09$)$ & 1.13 (1.06 to 1.21$)$ \\
\hline 4 & $26084(20.3)$ & $0.95(0.90$ to 1.00$)$ & 0.98 (0.92 to 1.04$)$ & 1.07 (1.00 to 1.15$)$ \\
\hline 5 (least deprived) & $25049(19.5)$ & 1 & 1 & 1 \\
\hline \multicolumn{5}{|l|}{ Comorbidity } \\
\hline \multicolumn{5}{|c|}{ Presence of (compared with absence): } \\
\hline Dementia & $15575(12.1)$ & $1.34(1.28$ to 1.41$)$ & 1.23 (1.16 to 1.30$)$ & 1.41 (1.33 to 1.50$)$ \\
\hline Lower RTI & $10112(7.9)$ & 1.85 (1.75 to 1.96$)$ & 1.95 (1.83 to 2.07$)$ & 1.26 (1.17 to 1.36$)$ \\
\hline Chronic IHD & $12739(9.9)$ & $1.89(1.80$ to 1.98$)$ & 2.12 (2.01 to 2.23) & 1.26 (1.17 to 1.35$)$ \\
\hline Heart failure & $6939(5.4)$ & 3.79 (3.59 to 4.00$)$ & 3.90 (3.68 to 4.13$)$ & 1.15 (1.04 to 1.27$)$ \\
\hline Diabetes mellitus & $9185(7.2)$ & $1.14(1.07$ to 1.21$)$ & $1.06(0.98$ to 1.14$)$ & 1.24 (1.15 to 1.34$)$ \\
\hline Renal failure & $2927(2.3)$ & 5.55 (5.12 to 6.03$)$ & 4.95 (4.56 to 5.39$)$ & 1.28 (1.09 to 1.51$)$ \\
\hline Malignancy & $3402(2.7)$ & $3.02(2.79$ to 3.27$)$ & 2.81 (2.57 to 3.07 ) & 1.14 (0.99 to 1.30$)$ \\
\hline Hypertension & $22526(17.6)$ & $0.88(0.84$ to 0.92$)$ & 0.87 (0.82 to 0.91$)$ & 0.93 (0.88 to 0.99$)$ \\
\hline
\end{tabular}

RTI=respiratory tract infection; IHD=ischaemic heart disease.

*950 patients excluded because of unknown fifth (missing or invalid postcode).

secondary diagnoses; the impact of adjustment was less for emergency readmissions.

After adjustment for all measured factors, the death rate increased with delay in operation, as shown by the adjusted odds ratios relative to at most one day's delay in figure 1 . There seems to be a decline after 12 days, which is probably due to some selection bias operating whereby more of the most ill patients had died before they could have an operation.

\section{Difference between observed and expected deaths}

We estimated differences between the observed number of deaths and the number expected with at most one day's delay for each trust. For a delay of more than one day, the sum of the dif-

Table 4 Odds ratios (95\% confidence interval) for death and readmission by intervention, adjusted for age, sex, deprivation fifth, and comorbidity

\begin{tabular}{|c|c|c|c|}
\hline & \multicolumn{3}{|c|}{ Outcome } \\
\hline & Death in hospital & $\begin{array}{l}\text { Death in hospital } \\
\text { within } 30 \text { days of } \\
\text { admission }\end{array}$ & $\begin{array}{c}\text { Emergency } \\
\text { readmission within } 28 \\
\text { days }\end{array}$ \\
\hline \multicolumn{4}{|l|}{ Intervention: } \\
\hline No procedure & $\begin{array}{c}3.33 \\
(3.15 \text { to } 3.51)\end{array}$ & 4.50 (4.25 to 4.77$)$ & 1.35 (1.24 to 1.46$)$ \\
\hline Other procedure & $\begin{array}{c}1.96 \\
(1.81 \text { to } 2.12)\end{array}$ & 2.28 (2.09 to 2.49$)$ & 1.05 (0.94 to 1.17$)$ \\
\hline Replacement & $\begin{array}{c}1.02 \\
\text { (0.98 to } 1.06)\end{array}$ & 0.99 (0.95 to 1.04$)$ & 1.02 (0.97 to 1.06$)$ \\
\hline Fixation & 1 & 1 & 1 \\
\hline \multicolumn{4}{|l|}{ Delay in operation*: } \\
\hline$>1$ day $v \leq 1$ day & $\begin{array}{c}1.27 \\
(1.23 \text { to } 1.32)\end{array}$ & 1.25 (1.19 to 1.31$)$ & 1.04 (0.99 to 1.08$)$ \\
\hline$>2$ days $v \leq 2$ days & $\begin{array}{c}1.43 \\
(1.37 \text { to } 1.49)\end{array}$ & 1.36 (1.29 to 1.43$)$ & 1.04 (0.99 to 1.10$)$ \\
\hline
\end{tabular}

*Replacement or fixation only. ference for all deaths in hospital was 1742 in three years (1435 to 2049), or $9.4 \%$ of the 18508 total deaths during that time. Half of the difference occurred in those aged $\geq 85$, with $24 \%$ in the 80-84 age group. Differences per year at trust level ranged from 17 fewer to 38 more deaths. Forty of the 151 trusts had fewer observed deaths than expected. For more than two days' delay, the total difference between the observed and expected deaths in three years was 1307 deaths (1202 to 1412), $7.1 \%$ of the 18508 total.

For deaths within 30 days of admission, the sum of the differences in the three years was 1155 (944 to 1366) for more than

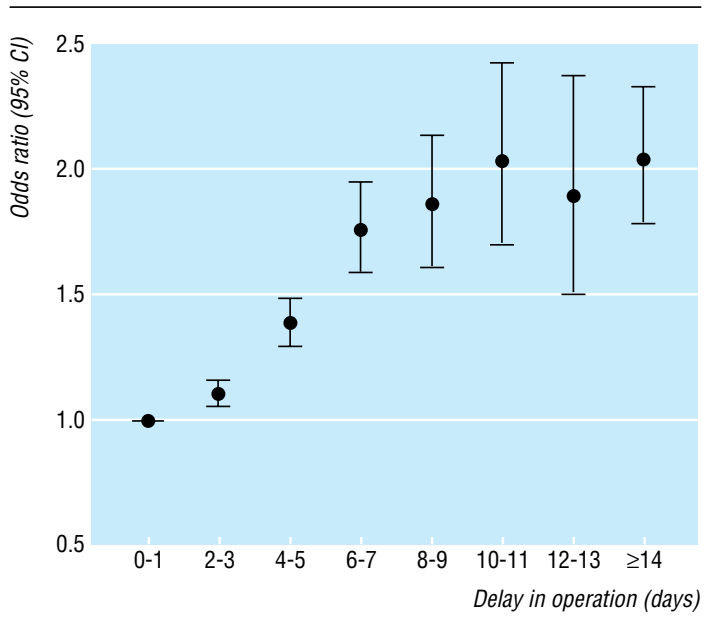

Fig 1 Odds ratios of death within hospital by operative delay relative to at most one day's delay, after adjustment for age, sex, deprivation, type of procedure (fixation and replacement only), and selected comorbidities 


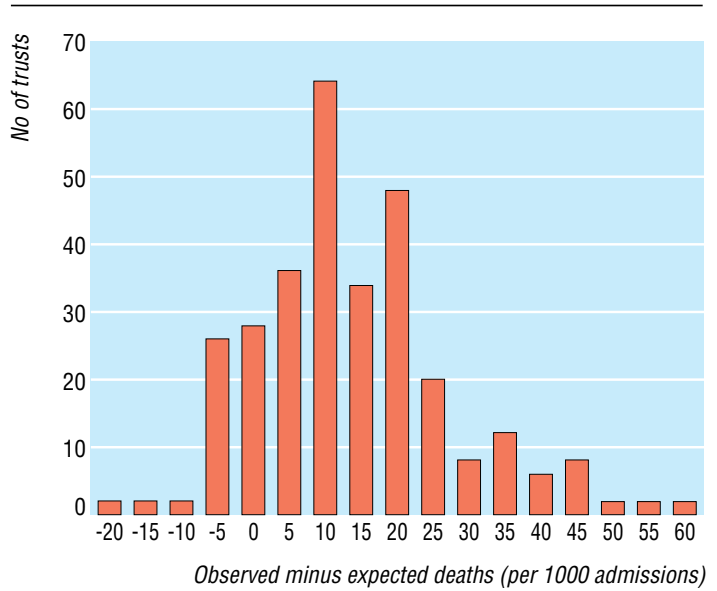

Fig 2 Mean annual difference between observed and expected deaths in hospital per 1000 admissions by trust associated with an operative delay of more than one day

one day's delay and 825 (752 to 898 ) for more than two days' delay. Differences per year at trust level ranged from 10 fewer to 23 more deaths for more than one day's delay.

At trust level, there were no significant relations overall between delay rates and (in turn) the proportion of patients managed medically $(\mathrm{P}=0.493)$, mortality $(\mathrm{P}=0.207)$, and the readmission rate $(\mathrm{P}=0.127)$. The 37 out of 151 trusts with more than half of their patients waiting more than one day for a fixation or replacement procedure, however, had significantly greater mean observed minus expected deaths than the other 114 (10.3, 0.8 to 19.8), after adjustment for volume by dividing the observed minus expected by the number of admissions and multiplying by 1000 to give a "difference per 1000 admissions." The trust with the largest difference (either raw or volume adjusted) had the second highest mortality and the 19th highest rate of delay. Figure 2 shows the differences per 1000 admissions by trust for the three years combined.

\section{Discussion}

Analysis of hospital episode statistics shows that after hip fracture a delay in operating was associated with a higher risk of mortality, even after we adjusted for available covariates. Although patients with a delayed procedure were on average only slightly older than those with no such delay, they were much more likely to have each of the comorbidity variables. The differences in the odds of death and the frequency of comorbidity also existed between patients managed surgically and those with no procedure. These findings suggest that comorbidity does indeed affect management, including the timing of operation, and that deleterious effect of delay remains after adjustment. If death rates in patients with at most one day's delay had been repeated throughout all 151 trusts in this study, there would have been an average of 581 fewer total deaths $(9.4 \%$ of the total) or 385 total 30 day deaths per year. Our results are broadly comparable with those of a recent study that found an operative delay of more than four days was associated with greater mortality'; the greater statistical power in our study enabled us to show the smaller effects of shorter delays (fig 1 ).

The estimation of the numbers of deaths associated with delayed operation requires the identification of all important factors that are related to both the risk of death and the timing of surgery. The reasons for delay can be divided into clinical and organisational; the expected deaths are assumed to take into account the first category for the purposes of the calculation. It would be wrong to conclude, however, that delaying surgery by more than 24 hours costs 581 lives per year in England. Some of these will be due to pre-existing disease, which might itself have caused the fall or the fracture, or both. This may be partly mitigated by considering deaths within 30 days of admission (a performance indicator used by the Department of Health ${ }^{10}$ ), which gave a total difference between observed and expected per year of 385 deaths. Some of these will be attributable to incomplete comorbidity coding and other unmeasured medical reasons for the delay.

\section{Study limitations}

Concerns about the quality of data from the hospital episode statistics remain. Although quality has improved greatly in recent years, data need careful interpretation. ${ }^{11}$ Like many systems for hospital data, the statistics do not capture deaths out of hospital, which will reduce reported in hospital mortality in trusts that discharge early. We were able to capture most transfers to other NHS hospitals so this will mainly affect discharges home or to residential homes. The timing of discharge is related to factors such as availability of rehabilitation beds, preoperative delay, and postoperative complications. ${ }^{12}$ The time between fracture and admission was also unknown and might be important. Deaths out of hospital are less important when we consider deaths within 30 days of admission, though this loss actually leads to an underestimate of the effect of operative delay.

A key factor influencing survival is mobility before the fracture. ${ }^{13}$ We included only patients admitted from their own homes, who are likely to be healthier than patients living in nursing homes, ${ }^{3}$ although this group also includes patients living in sheltered accommodation, who are likely to be more ill than patients living in their own home. Inclusion of the other patients showed that the place from which they were admitted was an important predictor of mortality (results not shown). The completeness of recording of comorbidity has been known to vary between trusts. ${ }^{14}$ Some trusts may systematically underrecord secondary diagnoses, which will lead to overestimating the effect of operative delay and hence also the difference between the observed and expected deaths. There is evidence that the recording of secondary diagnoses is increasing. We inspected all emergency admissions in the hospital episode statistics datasets and found that in 1996-7 only 29\% had one or more secondary diagnosis recorded; this increased to $55 \%$ the next year and rose to $60 \%$ in 2003-4. We used a diagnosis of Alzheimer's disease or dementia as an estimate of cognitive impairment but appreciate that this is a relatively insensitive measure of this important factor ${ }^{15}$; measures such as the American Society of Anaesthesiologists score are not recorded. A further problem is that the statistics cannot distinguish between chronic but stable disease and acute exacerbations.

Because the statistics may not record all comorbidities, residual confounding remains possible and indeed likely. By repeating the analysis after artificially increasing the number of patients with any comorbidity variable recorded and decreasing the numbers without, so that the total patients remained the same, we can estimate the effect of systematic under-recording on the odds ratio for delay. Doubling the proportion of patients with at least one comorbidity variable in this way (probably an extreme scenario) would reduce the odds ratio for 30 day mortality from 1.25 to 1.17 (1.12 to 1.22 ). The deprivation fifth will to some degree act as a proxy for preoperative health status and was shown to be correlated with both delay and mortality, though it had a stronger association with readmissions. 


\section{Readmissions}

Patients managed conservatively had the highest risk of emergency readmission, presumably because of the underlying pathology that made them unfit for surgery. For those having fixation or replacement procedures, we found little evidence for higher emergency readmission rates associated with surgical delay and the effect was much smaller than for mortality. Adjustment for comorbidity made much less difference to these odds ratios than it did for mortality.

\section{Conclusions}

Delayed operation after hip fracture was associated with an increased risk of death in hospital, which was reduced but still persisted we adjusted for comorbidity. There was large variation between trusts in operative delay. Hospital episode statistics could be used for monitoring purposes, with outlying trusts becoming the focus of further investigation to assess why operative delay, mortality in hospital, or readmission rates are increased.

\section{What is already known on this topic}

Over 60000 hip fractures occur every year in the UK

There is conflicting evidence from fairly small studies for the association between delay in operation and mortality, though Royal College of Physicians' guidelines recommend that patients be operated on within 24 hours of admission

Operation may be delayed to stabilise concomitant medical conditions

\section{What this study adds}

In England, 40\% of procedures were performed more than one day after admission

Proportions of patients waiting for more than one day or more than two days for their operation varies widely between trusts

Delay is associated with increased mortality: the association still exists but is reduced after adjustment for confounders
Contributors: $\mathrm{AB}$ and $\mathrm{PA}$ conceived the study. $\mathrm{AB}$ performed all analyses and is guarantor. $\mathrm{AB}$ and $\mathrm{PA}$ wrote the manuscript.

Funding: $\mathrm{AB}$ is $100 \%$ and $\mathrm{PA}$ is $50 \%$ funded by Dr Foster Ltd through a research grant for the unit.

Competing interests: The unit is funded by a grant from Dr Foster Ltd (an independent health service research organisation).

Ethical approval: We have approval to hold patient identifiable data granted by Security and Confidentiality Advisory Group with Section 60 support from the Patient Information Advisory Group (PIAG). We also have approval from St Mary's local research ethics committee.

1 Cooper C. Epidemiology and definition of osteoporosis. In: Compston JE, ed. Osteoporosis. New perspectives on causes, prevention and treatment. London: Royal College of Physicians of London, 1996:1-10.

2 Lyons AR. Clinical outcomes and treatment of hip fractures. Am J Med 1997;103:51-63S.

3 Holmberg S, Kalen R, Thorngren KG. Treatment and outcome of femoral neck fractures. An analysis of 2418 patients admitted from their own homes. Clin Orthop 1987;218:42-52.

4 Rogers FB, Shackford SR, Keller MS. Early fixation reduces morbidity and mortality in elderly patients with hip fractures from low-impact falls. J Trauma 1995;39:261-5.

5 Fox HJ, Pooler J, Prothero D, Bannister GC. Factors affecting the outcome after proxiFox H, Pooler J, Pro h. Banis

6 Royal College of Physicians. Fractured neck of femur:prevention and management. London: Royal College of Physicians of London, 1989.

7 Department of the Environment, Transport and the Regions. Indices of deprivation 2000. London: DETR, 2000. (Regeneration Research Summary No 31.)

8 Wolfinger RD. Fitting nonlinear mixed models with the new NLMIXED procedure. Cary, NC: SAS Institute, 1999. (Paper 287.) www2.sas.com/proceedings/sugi24/Stats/p28724.pdf (accessed Feb 2006)

9 Moran C, Wenn RT, Sikand M, Taylor AM. Early mortality after hip fracture: is delay before surgery important? J Bone Joint Surg (Am) 2005;87:483-9.

10 Healthcare Commission. Performance indicators $2005 . \quad$ http:// ratings.healthcarecommission.org.uk/Indicators_2005/Trust/Indicator/ indicators.asp?trust Type $=1$ (accessed June 2005)

11 Hansell A, Bottle A, Shurlock L, Aylin P. Accessing and using hospital activity data. J Pub Health Med 2001;21:51-6.

12 Turner P, Cocks J, Cade R, Ewing H, Collopy B, Thompson G. Fractured neck of the femur (DRG 210/211): prospective outcome study. Aust N Z J Surg 1997:67:126-30.

13 Holt EM, Evans RA, Hindley CJ, Metcalfe JW. 1000 femoral neck fractures: the effect of pre-injury mobility and surgical experience on outcome. Injury 1994;25:91-5.

14 McKee M. Routine data: a resource for clinical audit? Qual Health Care 1993;2:104-11.

15 Cree M, Soskolne CL, Belseck E, Hornig J, McElhaney JE, Brant R, et al. Mortality and institutionalization following hip fracture. J Am Geriatr Soc 2000;48:283-8.

(Accepted 15 February 2006)

doi 10.1136/bmj.38790.468519.55

Dr Foster Unit at Imperial College London, Department of Primary Care and Social Medicine, Imperial College London, London W6 8RP Alex Bottle research associate

Paul Aylin clinical senior lecturer in epidemiology and public health

Correspondence to: A Bottle robert.bottle@imperial.ac.uk 